\title{
Cascade Signals of Papaverine Inhibiting LPS-Induced Retinal Microglial Activation
}

\author{
Ting Zhou ${ }^{1} \cdot$ Yu Zhu ${ }^{1}$ \\ Received: 12 January 2019 / Accepted: 28 February 2019 / Published online: 9 March 2019 \\ (C) Springer Science+Business Media, LLC, part of Springer Nature 2019
}

\begin{abstract}
Studies have shown that papaverine can inhibit lipopolysaccharide (LPS)-induced microglial activation. The retinal primary microglia of newborn SD rats were isolated and purified, and a LPS-induced microglia activation model was established. The protein phosphorylation level of the signaling pathway was detected by western blotting. The transcription and expression of TNF- $\alpha$, IL$1 \beta$, and IL-10 were respectively detected by RT-PCR and ELISA to observe the abnormal activation of primary microglia. The cAMP inhibitor Rp-isomer, PKA inhibitor H89, and MEK inhibitor U0126 were separately added to further investigate the role of MEK/Erk in PAP inhibition of primary microglial activation and the relationship between cAMP/PKA and MEK/Erk. It was found that the level of MEK phosphorylation was upregulated after LPS stimulation, which was blocked by $10 \mu \mathrm{g} / \mathrm{ml}$ of papaverine. $10 \mu \mathrm{M}$ U0126 significantly inhibited TNF- $\alpha$ and IL-1 $\beta$ and increased IL-10 transcription and expression in retinal microglia $(P<0.01)$. Both Rp-isomer and H89 upregulated the phosphorylation levels of MEK and Erk. Papaverine may inhibit inflammatory factors and promote the expression of anti-inflammatory factors through the cAMP/PKA and MEK/Erk pathway, thereby inhibiting LPSinduced activation of primary retinal microglia, and the MEK/Erk pathway may be partially regulated by cAMP/PKA, which can provide theoretical basis and experimental basis for its protection of the central nervous system.
\end{abstract}

Keywords Papaverine $\cdot$ Primary microglia $\cdot$ MEK/Erk $\cdot$ cAMP/PKA

\section{Introduction}

Papaverine is a non-selective PDE inhibitor that relaxes cardiovascular, respiratory, and gastrointestinal smooth muscles and is commonly used in cerebral thrombosis, pulmonary embolism, and arterial spasm (Zhu et al. 2014; Kim et al. 2014). In recent years, its role in inhibiting microglia immune inflammation and central nervous system protection has gradually received attention. Yoshikawa et al. first found that papaverine could inhibit release of TNF- $\alpha$ and IL-1 $\beta$ in LPS-induced BV2 cells (Yoshikawa et al. 1999). Our study also found that papaverine inhibited the activation of primary retinal microglia by inhibiting the expression of inflammatory factors and promoting the expression of anti-inflammatory factors.

Yu Zhu

13673666718@163.com

Ting Zhou

tyzxzt@126.com

1 Department of Ophthalmology, The First Affiliated Hospital of Zhengzhou University, East Jianshe Road, Zhengzhou 450001, People's Republic of China
Activation of microglia is a double-edged sword (Loane and Kumar 2016), and functional changes in activated microglia mainly include enhanced phagocytic capacity and release of inflammatory mediators (Kettenmann et al. 2011). In the early stage of central nervous system inflammation, activated microglia can limit the spread of inflammation, phagocytose pathogens, and play a neuroprotective role (Namiki et al. 2000; Iannotti et al. 2004), which helps maintain central nervous system homeostasis (Kettenmann et al. 2011). The downside is that chronic abnormally activated microglia release inflammatory mediators and excessively phagocytose injured neurons. Recent studies have shown that abnormally activated microglia can phagocytose active neurons under stress, which called phagocytic apoptosis (Brown and Neher 2014). Inflammatory mediators play a central role in neurodegenerative diseases (Alam et al. 2016), while microglia are the major cells that release inflammatory mediators (Buttini et al. 1997; Ghosh et al. 2012). TNF- $\alpha$ and IL-1 $\beta$ are cytotoxic inflammatory mediators released by microglia in early retinal injury, which initiate a series of cellular responses, including activation and migration of microglia and astrocytes (Pousset et al. 1999; Milner and Campbell 2002; Tanuma et al. 2006). Some studies had shown that inhibition of TNF- $\alpha$ and IL-1 $\beta$ 
could significantly reduce ganglion cell apoptosis (Sivakumar et al. 2011). In some cases, inhibition of activated microglia could increase the release of anti-inflammatory factors, such as IL-10 (Yoshikawa et al. 1999; Mizuno et al. 2004; Woo et al. 2004; Schafer 2012) to protect central nervous cells and promote axonal regeneration. Mizuno et al. found that Ibudialast can increase the expression of IL-10, NGF, and GDNF and inhibit neuronal apoptosis in a dose-dependent way (Mizuno et al. 2004).

Our preliminary experiments had proposed that papaverine inhibited the release of inflammatory cytokines in primary retinal microglia. However, further mechanisms remain unclear. Dang et al. found that tetrandrine could inhibit the activation of BV2 cells by inhibiting NF-kB and ERK signaling pathways (Dang et al. 2014). Mitogen-activated protein kinases (MAPKs) are essential signaling molecules involved in the control of a variety of macrophage mediators. Studies have shown that MAPKs are involved in microglial activation and appear to play crucial roles in the inflammatory process (Kim et al. 2004; Zhang and Dong 2007). To further investigate the mechanism of papaverine inhibition of microglial activation, we investigated the involvement of MEK/Erk during the activation of microglia and analyzed the relationship between cAMP/PKA and MEK/Erk signaling pathway, which could explore the mechanism of papaverine regulating the functional status of retinal microglia and provide theoretical basis and experimental basis for its protection of the central nervous system.

\section{Methods}

\section{Cell Culture and Treatment}

Retina primary microglia were isolated from SD rats provided by the Experimental Animal Center of Zhengzhou University. Cells were cultured in medium containing DMEM/F12 (Hyclone, GE Healthcare), 10\% fetal bovine serum (FBS), and $1 \%$ penicillin/streptomycin. Cells were pretreated with cAMP inhibitor Rp-isomer(200 $\mu$ mol,C0735-1VL,Sigma, USA), PKA inhibitor H89(5 $\mu \mathrm{mol}, 9844, C S T)$ and Erk inhibitor U0126 (10 $\mu \mathrm{mol}, \mathrm{HY}-12031, \mathrm{MCE})$ for $1 \mathrm{~h}$, papaverine (10 $\mu \mathrm{g} / \mathrm{ml}, 120,901-1$, Northeast Pharmaceutical Group Co. Ltd., China) for $4 \mathrm{~h}$, and incubated with LPS (100 $\mathrm{ng} / \mathrm{ml})$ for $24 \mathrm{~h}$. All animals used for cell culture were approved by the institutional committee of the Animal Research Committee and the Animal Ethics Committee of Zhengzhou University.

\section{Western Blotting}

To extract total cell protein, cells were centrifuged and collected, and washed three times with PBS for $3 \mathrm{~min}$. One hundred microliters of RIPA lysate was added and calls were lysed on ice for half an hour. The extracted protein was detected using the BCA method. Absorbance value was measured by the microplate reader; The protein concentrations of samples were calculated from the standard curve. Samples were analyzed on $10 \%$ SDS-PAGE gels and transferred to NC membranes. Then the NC membrane was placed into a blocking solution $(5 \%$ skim milk powder dissolved in TBST) for $1 \mathrm{~h}$. Primary antibodies were added and incubated overnight at $4{ }^{\circ} \mathrm{C}$. On the next day, after secondary antibodies added, samples were incubated in the dark for $1-2 \mathrm{~h}$ at room temperature. The $\mathrm{NC}$ membrane was infiltrated with the mixed chemiluminescence reagent. Images were analyzed and the gray value was analyzed by Image J software. The specific primary antibodies included Phospho-MEK1/2 (\#9154, Cell Signaling, USA), Phospho-ERK1/2 (214362, Abcam), and $\beta$-actin (ab3280, Abcam). Experiments were repeated at more than three times.

\section{Reverse Transcription PCR}

Total RNA was extracted using Trizol reagent according to the instructions provided by the suppliers, and the RNA concentration was measured using a nucleic acid micro spectrophotometer. RNA was reverse-transcribed using a HiScript ${ }^{\circledR}$ II Q RT SuperMix kit(R223-01, Vazyme, China). Then, cDNA was amplified by PCR. The reaction conditions for amplifying DNA were $95^{\circ} \mathrm{C}$ for $10 \mathrm{~min}$, followed by 40 cycles, each cycle consisting of $95^{\circ} \mathrm{C}$ for $10 \mathrm{~s}$ and $60^{\circ} \mathrm{C}$ for $30 \mathrm{~s}$, and testing with the ABI 7500Fast. The mRNA expression was normalized to the expression level of GAPDH. The sequencespecific oligonucleotide primers were as follows: TNF- $\alpha$ forward: AGACCCTCACACTCAGATCA, reverse: GTCTTTGAGATCCATGCCATTG; IL- $1 \beta$ forward: CACCTCTCAAGCAGAGCACAG, reverse: GGGTTCCA TGGTGAAGTCAAC; IL-10 forward: GCCAAGCC TTGTCAGAAATGA, reverse: TTTCTGGGGCCATG GTTCTCT; GAPDH forward: TGCACCACCAACTG CTTAGC, reverse: GCCCCACGGCCATCA. The results were calculated using the $2^{-\triangle \Delta \mathrm{ct}}$ method, and statistical analysis was performed. Experiments were repeated at more than three times.

\section{Enzyme-Linked Immunosorbent Assay}

The culture mediums were collected and centrifuged to remove floating cells. The supernatant was used for ELISA assay. The expression of TNF- $\alpha$, IL-1 $\beta$, and IL-10 was measured using an ELISA kit in accordance with the protocol provided by the manufacturer. Briefly, different samples and the detection antibody were added to each well. After incubated for $30 \mathrm{~min}$, the plates were washed, and aenzyme and chromogenic substrate were added. Then stop solution was added to terminate the reaction. Finally, the absorbance value at $450 \mathrm{~nm}$ was measured with a microplate reader to determine 
the concentration of each well. ELISA kits used were Rat cAMP ELISA kit (ab133039, Abcam), Rat TNF- $\alpha$ ELISA kit (12-3720, Dakewe, China), Rat IL-1 $\beta$ ELISA kit (123012, Dakewe, China), and Rat IL-10 ELISA kit(12-3100, Dakewe, China). Experiments were repeated at more than three times.

\section{Statistical analyses}

Data were expressed as the mean $\pm \mathrm{SEM}$ (standard error of the mean). Statistical significance of the differences between experimental groups was evaluated by one-way analysis of variance followed by Dunnett's test. The differences between two groups were assessed using $t$ test. Differences were considered statistically significant at $P<0.05$.

\section{Results}

\section{Effects of Papaverine on the Transcription and Expression of TNF- $\alpha$, IL- $1 \beta$, and IL-10}

Papaverine dose-dependently suppressed mRNA expression of TNF- $\alpha$ and IL- $1 \beta$ in LPS-stimulated microglia $(n=5 ; P<0.05$ compared with the LPS group, Fig.1a), and these results were consistent with changes in TNF- $\alpha$ and IL-1 $\beta$ expression $(n=5$; $P<0.05$ compared with the LPS group, Fig.1b).
The addition of LPS enhanced the transcription and expression of IL-10, and pretreatment of PAP was able to further enhance these effects $(n=5 ; P<0.05$ compared with the LPS group, except for the $0.4 \mu \mathrm{g} / \mathrm{ml}$ group, Fig.2).

\section{Papaverine Suppresses TNF- $\alpha$ and IL-1 $\beta$ by Activating CAMP/PKA Signaling Pathway}

The expression of cAMP was detected by ELISA. As shown in Fig.3a, primary retinal microglia were divided into three groups after digestion and adherence: (1) normal medium; (2) $10 \mu \mathrm{g} / \mathrm{ml}$ papaverine pretreated for $30 \mathrm{~min}$; (3) $10 \mu \mathrm{g} / \mathrm{ml} \mathrm{pa-}$ paverine pretreated for $30 \mathrm{~min}$ and incubated with LPS for $1 \mathrm{~h}$. Treatment with $10 \mu \mathrm{g} / \mathrm{ml}$ of papaverine significantly upregulates $\operatorname{cAMP}(2.219 \pm 0.090 \mathrm{pmol} / \mathrm{ml} ; n=5 ; P<0.01$ compared with the control group), while after $1 \mathrm{~h}$ of LPS treatment, cAMP is significantly decreased $(1.256 \pm 0.082 \mathrm{pmol} /$ $\mathrm{ml} ; n=5 ; P<0.01$ compared with the PAP group).

Then, we determined whether activation of the cAMP/ PKA pathway leads to inhibition of TNF- $\alpha$ and IL-1 $\beta$. We used the cAMP inhibitor Rp-isomer $(200 \mu \mathrm{mol})$ and the PKA inhibitor H89 $(5 \mu \mathrm{mol})$ to block the cAMP/PKA pathway. The expression level of TNF- $\alpha$ and IL-1 $\beta$ were detected by ELISA. The results showed us that inhibition of the cAMP/ PKA pathway could increase the release of TNF- $\alpha$ and IL-1 $\beta$. As shown in Fig.3b, we found that papaverine could significantly inhibit the expression of TNF- $\alpha$ and IL- $1 \beta$ which
Fig. 1 The transcription and expression of TNF- $\alpha$ and IL- $1 \beta$ after papaverine pretreatment. Primary microglia were pretreated with papaverine $(0,0.4,2$, and $10 \mu \mathrm{g} / \mathrm{ml})$ for $4 \mathrm{~h}$ and incubated with LPS $(100 \mathrm{ng} / \mathrm{ml})$ for another $24 \mathrm{~h}$. a The transcription of TNF$\alpha$ and IL- $1 \beta$ were detected by RTPCR $(n=5)$. b The expression of TNF- $\alpha$ and IL- $1 \beta$ were detected by ELISA $(n=5)$. $* P<0.05$ versus LPS group, $* * P<0.01$ versus LPS group
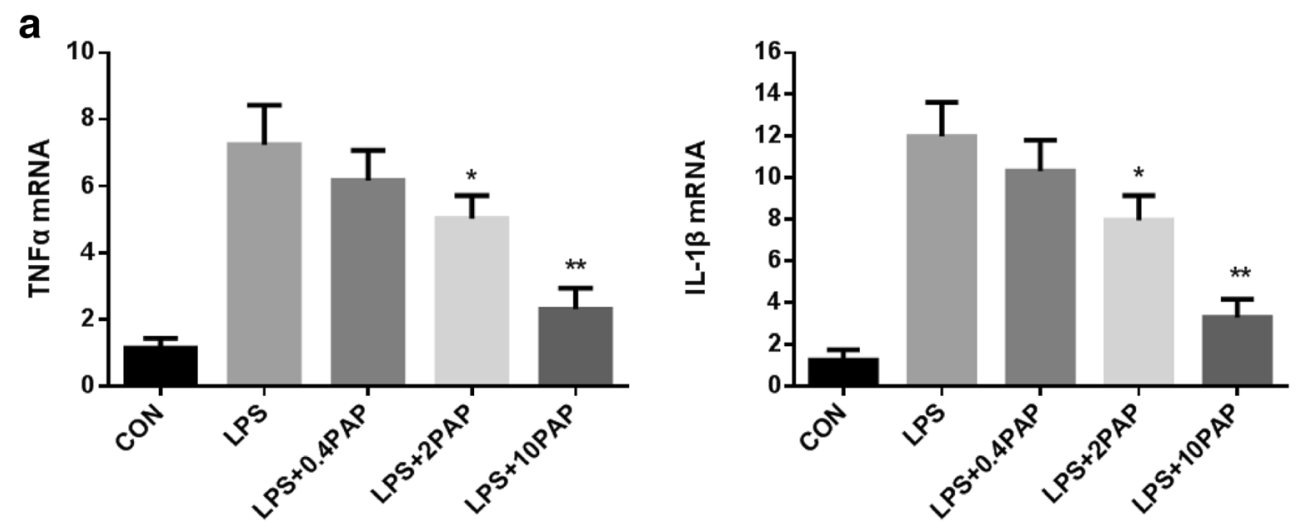

b
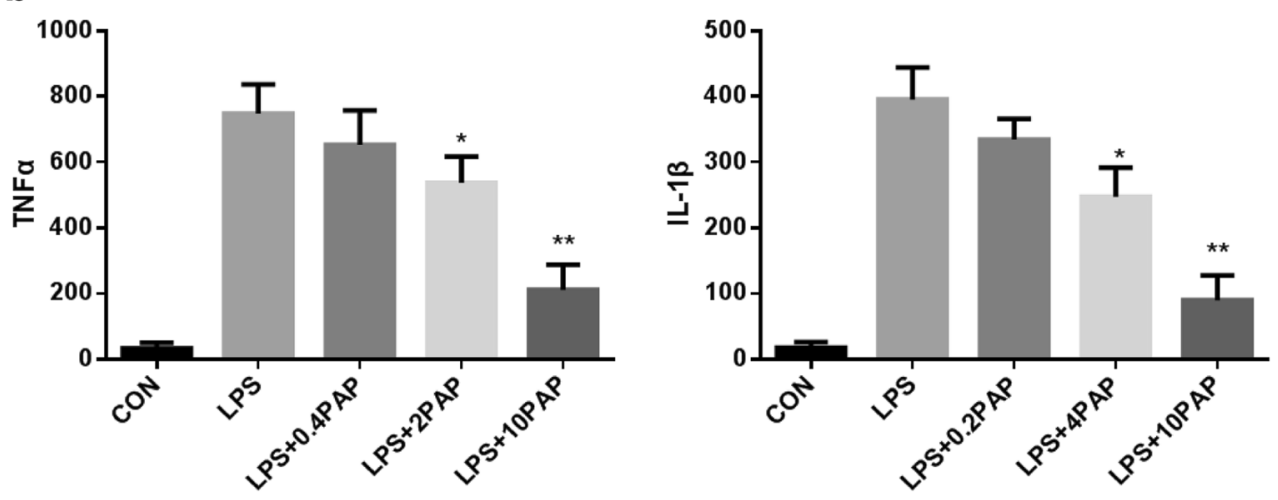
Fig. 2 The transcription and expression of IL-10 after papaverine pretreatment. Primary microglia were pretreated with papaverine $(0,0.4,2$, and $10 \mu \mathrm{g} / \mathrm{ml})$ for $4 \mathrm{~h}$ and stimulated by LPS for another 1 day. The transcription and expression of IL-10 were detected by RT-PCR and ELISA, respectively $(n=5) . * P<0.05$ versus LPS group, $* * P<0.01$ versus LPS group
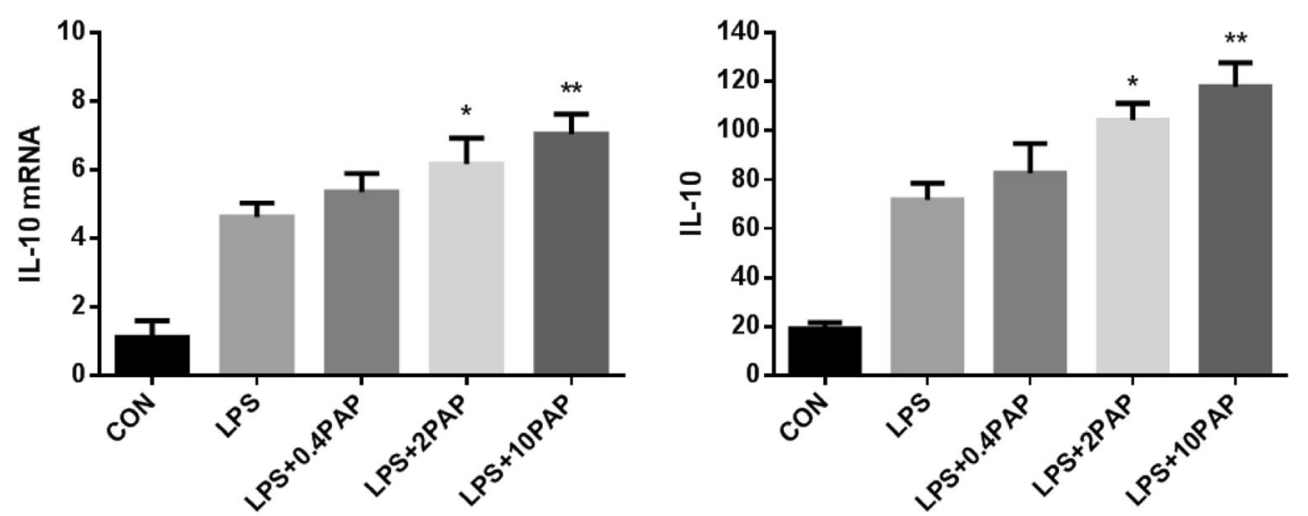

upregulated by LPS ( $n=5 ; P<0.01$ compared with the LPS group). After adding Rp-isomer, the expression of TNF- $\alpha$ and IL-1 $\beta$ were increased $(n=5 ; P<0.01$ compared with the
LPS+PAP group). Similarly, the expression of TNF- $\alpha$ and IL-1 $\beta$ were increased after adding H89 $(n=5 ; P<0.01$ compared with the LPS+PAP group).

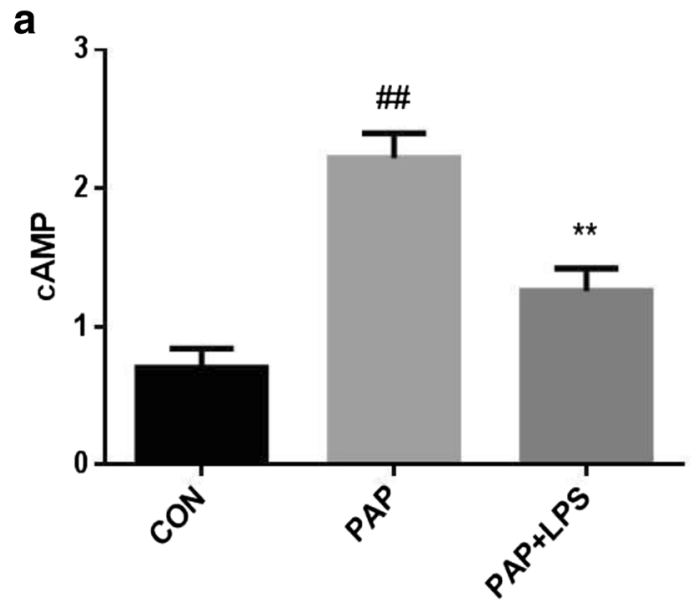

b

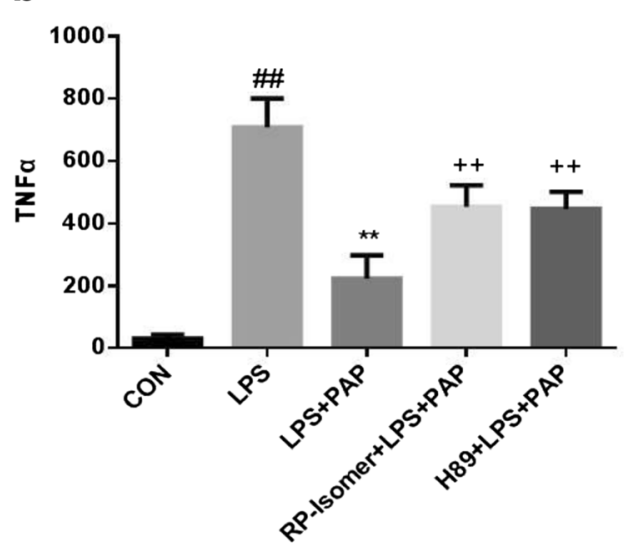

Fig. 3 Papaverine suppresses TNF- $\alpha$ and IL- $1 \beta$ by cAMP/PKA signaling pathway. a Treatment with $10 \mu \mathrm{g} / \mathrm{ml}$ of papaverine significantly upregulates cAMP ( $n=5, P<0.01$ compared with $\mathrm{CON}$ group), while LPS can partly inhibit the increase of cAMP $(n=5, P<0.01$ compared with PAP group; $P<0.05$ compared with $C O N$ group). \#\#P $<0.01$ versus CON group, $* * P<0.01$ versus PAP group. b Primary retinal microglia were pretreated with $200 \mu \mathrm{mol} \mathrm{Rp}$-isomer and $5 \mu \mathrm{mol} \mathrm{H} 89$ for $30 \mathrm{~min}$, then treated with $10 \mu \mathrm{g} / \mathrm{ml}$ of papaverine for $4 \mathrm{~h}$, and finally incubated

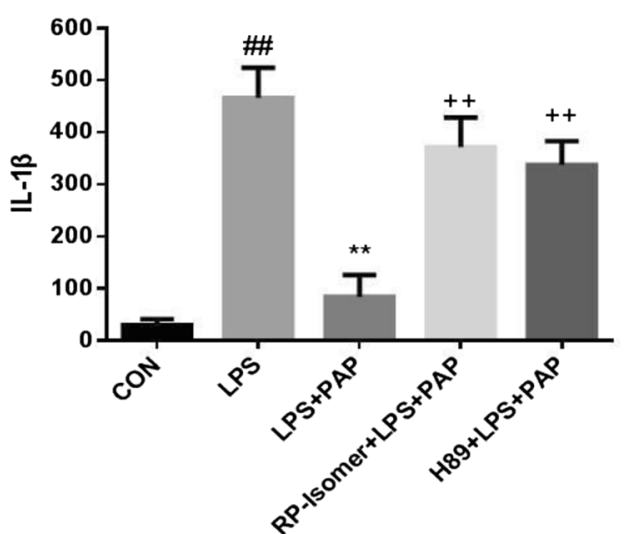

with $100 \mathrm{ng} / \mathrm{ml}$ LPS for $1 \mathrm{~h}$. The expression level of TNF- $\alpha$ and IL-1 $\beta$ were detected by ELISA. The results showed that papaverine could inhibit the expression of TNF- $\alpha$ and IL- $1 \beta$ which upregulated by LPS $(n=$ 5). After adding Rp-isomer, the expression of TNF- $\alpha$ and IL- $1 \beta$ were increased $(n=5)$. Similarly, the expression of TNF- $\alpha$ and IL- $1 \beta$ were increased after adding H89 $(n=5)$. \#\#P<0.01 versus CON group, $* * P<0.01$ versus LPS group, $++P<0.01$ versus LPS + PAP group 


\section{Papaverine Downregulates MEK/Erk Signaling Pathway}

The phosphorylation levels of MEK and Erk were detected by Western Blotting. As shown in Fig. 4, the expression of pMEK and p-Erk were upregulated after stimulation with LPS at $100 \mathrm{ng} / \mathrm{ml}$ for $1 \mathrm{~h}(1.21 \pm 0.033,1.209 \pm 0.053$,

a

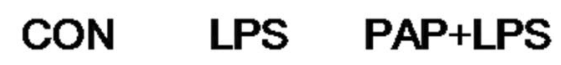

\section{MEK \\ p-MEK \\ ERK \\ p-ERK \\ $\beta$-actin}

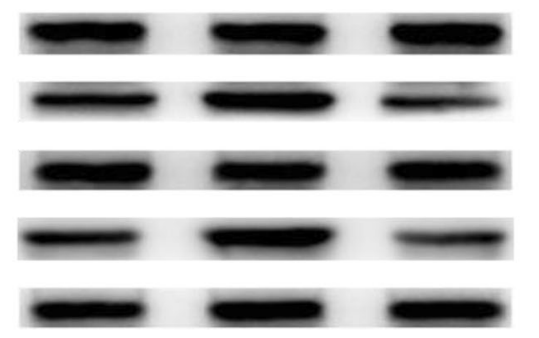

b

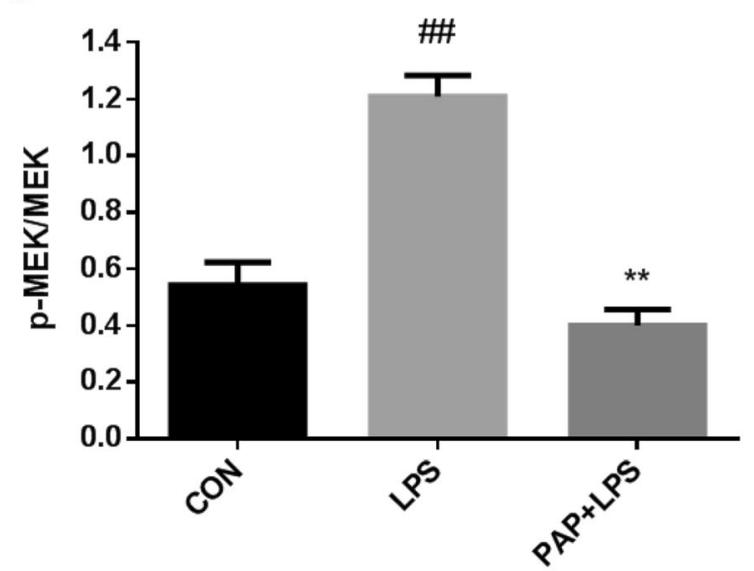

C

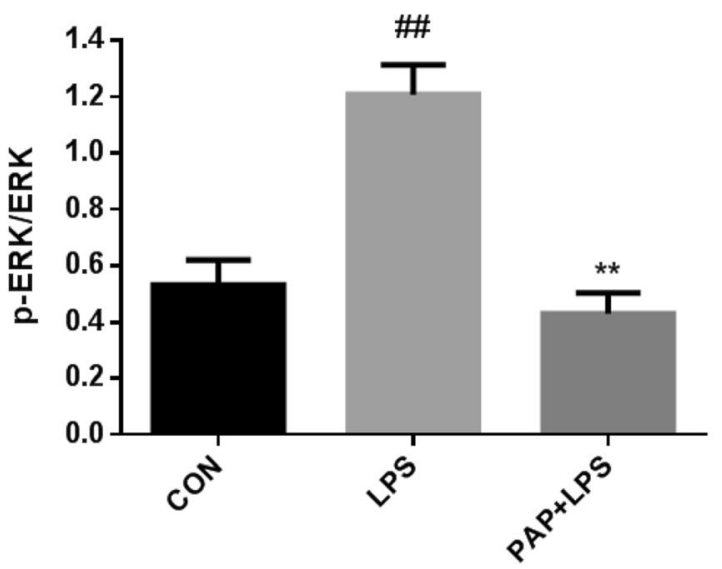

Fig. 4 a-c Papaverine inhibited phosphorylation of MEK and Erk in LPS-induced microglia. Primary retinal microglia were pretreated with $10 \mu \mathrm{g} / \mathrm{ml}$ papaverine for $4 \mathrm{~h}$, and $100 \mathrm{ng} / \mathrm{ml}$ of LPS was added for further $1 \mathrm{~h}$. The cells were lysed, total protein was extracted, and the expression of phosphorylated MEK and Erk were detected by Western Blotting. The results showed that LPS significantly upregulated the phosphorylation levels of MEK and Erk, and papaverine blocked the above effects $(n=$ 4). \#\#P<0.01 versus CON group, $* * P<0.01$ versus LPS group respectively; $n=4 ; P<0.01$ compared with the control group), and these effects were blocked by $10 \mu \mathrm{g} / \mathrm{ml}$ of papaverine $(0.399 \pm 0.026,0.43 \pm 0.037$, respectively; $n=4$; $P<0.01$ compared with the LPS group).

\section{U0126 Attenuates the Transcription and Expression of Inflammatory Factors TNF- $\alpha$ and IL-1 $\beta$}

We next determined whether inhibition of the MEK/Erk pathway results in inhibition of microglial activation. The results showed us that activation of the MEK/Erk pathway could increase the release of inflammatory factors such as TNF- $\alpha$ and IL-1 $\beta$. As shown in Fig.5, the transcription level of inflammatory factors was detected by RT-PCR, and it was found that $100 \mathrm{ng} / \mathrm{ml}$ of LPS increased 7.4-fold TNF- $\alpha$ mRNA and 8.5-fold IL-1 $\beta$ mRNA $(n=5 ; P<0.01$ compared with the control group, Fig.5a) compared with physiological state, while addition of $10 \mu \mathrm{M} \mathrm{U} 0126$ significantly inhibited retinal microglia $61.1 \%$ TNF- $\alpha$ mRNA and $65.4 \%$ IL- $1 \beta$ mRNA $(n=$ 5; $P<0.01$ compared with the LPS group, Fig.5a), the mRNA of TNF- $\alpha$ and IL- $1 \beta$ after using papaverine+U0126 were less than using U0126 alone, but it was not statistically significant ( $n=5 ; P=0.538,0.505$, respectively, compared with the U0126+LPS group; Fig.5a).

Consistent with the results of PT-PCR, the expression level of inflammatory factors was detected by ELISA, and found that the content of TNF- $\alpha$ and IL- $1 \beta$ was low under physiological conditions, while LPS upregulated 23.8 times TNF- $\alpha$ and 16.2 times IL-1 $\beta$ ( $n=5$; compared with the control group, $P<0.01$, Fig. 5b). The expression levels of TNF- $\alpha$ and IL-1 $\beta$ were significantly reduced after adding $\mathrm{U} 0126(n=5$; compared with the LPS group, $P<0.01$, Fig.5b), and the expression of TNF- $\alpha$ and IL-1 $\beta$ in papaverine+U0126+LPS group was less than in U0126+LPS group, but it was not statistically significant $(n=5 ; P=0.086,0.424$, respectively, compared with the U0126+LPS group; Fig.5b).

\section{U0126 Increases Transcription and Expression of the Anti-Inflammatory Factor IL-10}

As shown in Fig.6, the transcription of IL-10 was detected by RT-PCR, and it was found that LPS increased IL-10 mRNA compared with physiological state and $10 \mu \mathrm{M}$ U0126 further increase IL-10 mRNA( $n=5$; compared with the LPS group, $P<0.05$, Fig.6), and the mRNA of IL-10 after using papaverine+U0126 were higher than using U0126 alone, but it was not statistically significant $(n=5 ; P=0.402$ compared with the U0126+LPS group; Fig.6).

Consistent with the results of PT-PCR, the expression level of IL-10 was detected by ELISA, and found that a certain amount of IL-10 existed under physiological conditions, while LPS upregulated IL-10, addition of U0126 further increase IL$10(n=5$; compared with the LPS group, $P<0.05$, Fig.6), and 
Fig. 5 a, b U0126 inhibited the transcription and expression of TNF- $\alpha$ and IL-1 $\beta$. Primary retinal microglia were pretreated with $10 \mu \mathrm{mol} \mathrm{U} 0126$ for $1 \mathrm{~h}$, then treated with $10 \mu \mathrm{g} / \mathrm{ml}$ of papaverine for $4 \mathrm{~h}$, and finally added with $100 \mathrm{ng} / \mathrm{ml}$ LPS for $1 \mathrm{~h}$. The cells were harvested, RNA was extracted, the cDNA was synthesized, and the concentration of TNF- $\alpha$ mRNA and IL- $1 \beta$ mRNA were detected by RT-PCR. The supernatant was collected and the concentrations of TNF- $\alpha$ and IL$1 \beta$ were detected by ELISA. The results showed that U0126 significantly inhibited the transcription (a) and expression (b) of TNF- $\alpha$ and IL- $1 \beta$ that upregulated by LPS ( $n=5, P<0.01$ compared with the LPS group). $* * P<0.01$ versus LPS group a
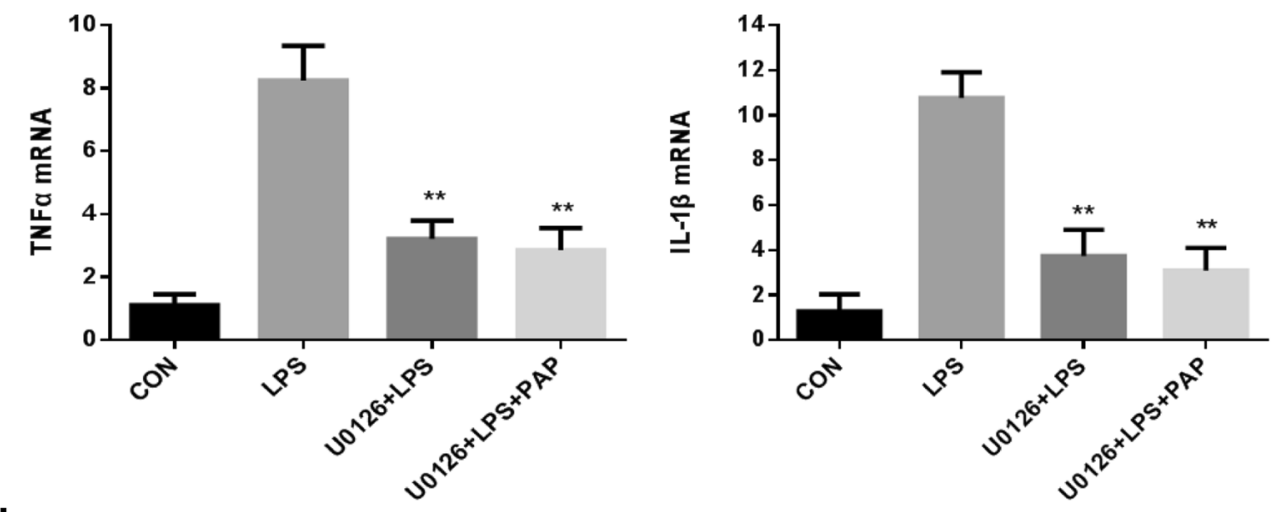

b
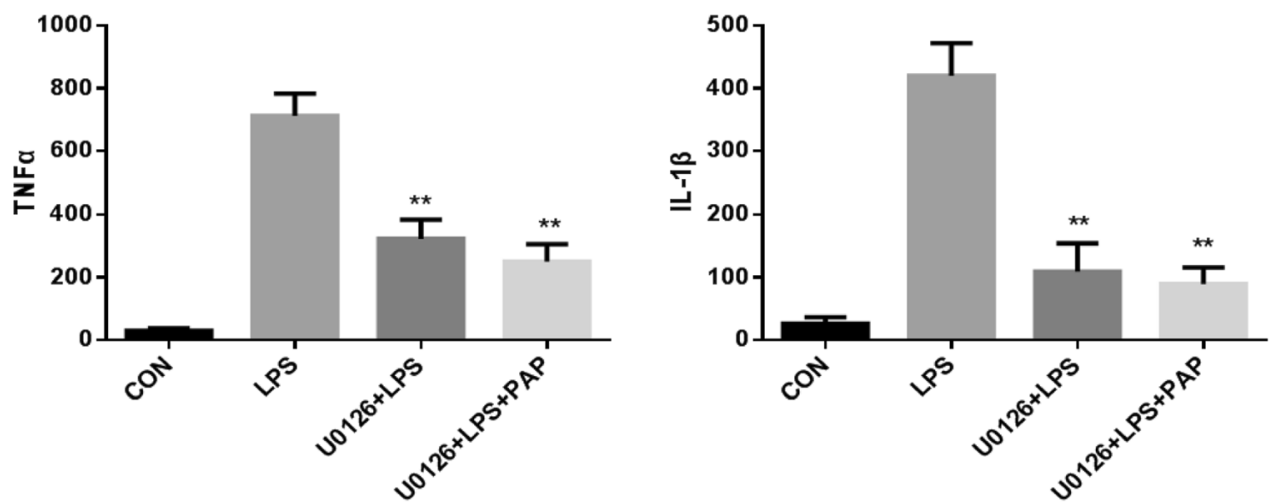

the expression of IL-10 in papaverine+U0126+LPS group were higher than in U0126+LPS group, but it was not statistically significant $(n=5 ; P=0.252$ compared with the U0126+LPS group; Fig.6).

\section{The Activation of the MEK/Erk Pathway Is Regulated by the CAMP/PKA Pathway}

In this study, we found that papaverine could activate the cAMP and inhibit the activation of the MEK/Erk pathway.

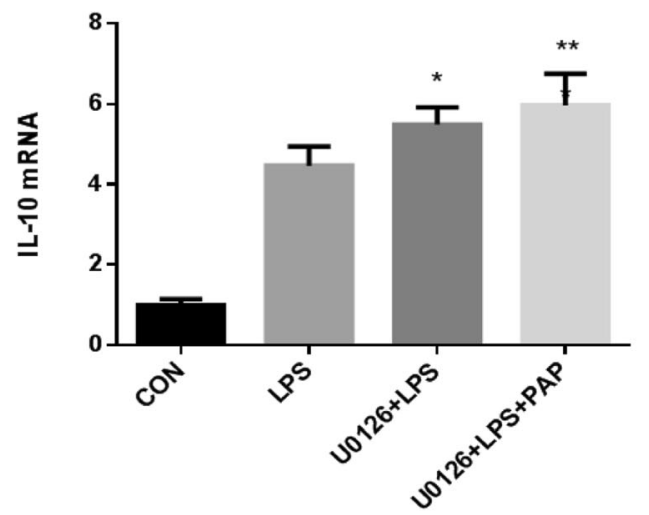

Fig. 6 U0126 increased the transcription and expression of IL-10. Primary retinal microglia were pretreated with $10 \mu \mathrm{mol}$ of U0126 for $1 \mathrm{~h}$, then treated with $10 \mu \mathrm{g} / \mathrm{ml}$ of papaverine for $4 \mathrm{~h}$, and finally added with $100 \mathrm{ng} / \mathrm{ml}$ of LPS for $1 \mathrm{~h}$. Cells were harvested and RNA was extracted. The cDNA was synthesized and the concentration of IL-10
However, the relationship between the two pathways is not well understood. Therefore, we added the cAMP inhibitor Rpisomer $(200 \mu \mathrm{mol})$ and the PKA inhibitor H89 $(5 \mu \mathrm{mol})$ to block the cAMP/PKA pathway. The phosphorylation of MEK and Erk were detected by Western Blotting. As shown in Fig. 7, after $1 \mathrm{~h}$ of LPS stimulation, the phosphorylation levels of MEK and Erk were significantly upregulated (1.618 \pm $0.071,1.528 \pm 0.054$, respectively; $n=6 ; P<0.01$ compared with the control group), and papaverine reversed the above effects $(0.314 \pm 0.054,0.35 \pm 0.042$, respectively; $n=6$;

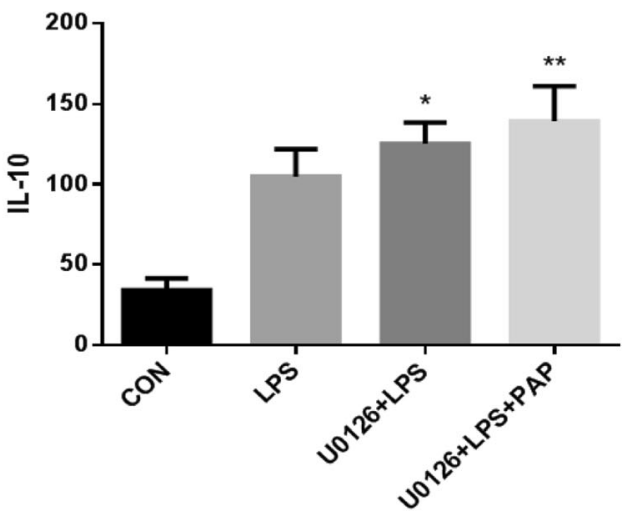

mRNA was detected by RT-PCR. The supernatant was collected and the concentration of IL-10 was detected by ELISA. The results showed that U0126 can further upregulate the transcription and expression of IL$10(n=5, P<0.01$ compared with the LPS group). $* P<0.05$ versus LPS group, $* * P<0.01$ versus LPS group 


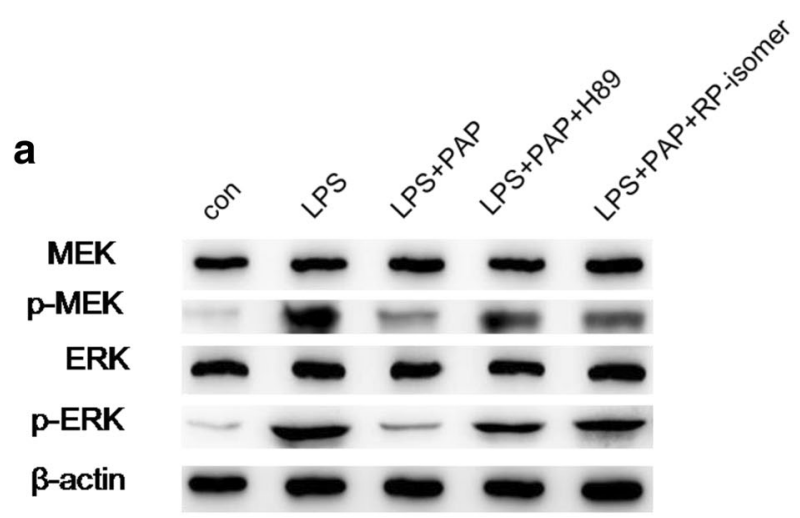

b

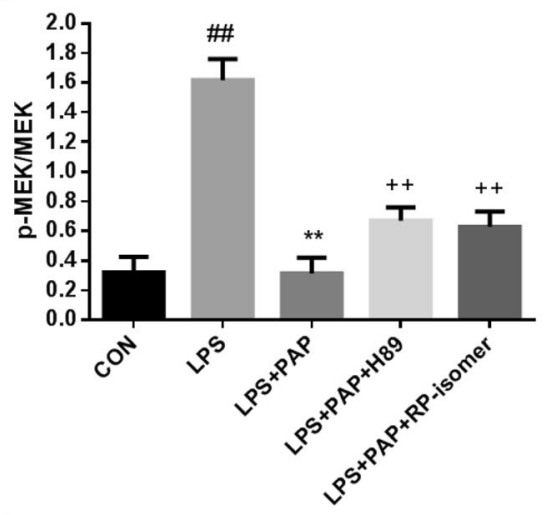

C

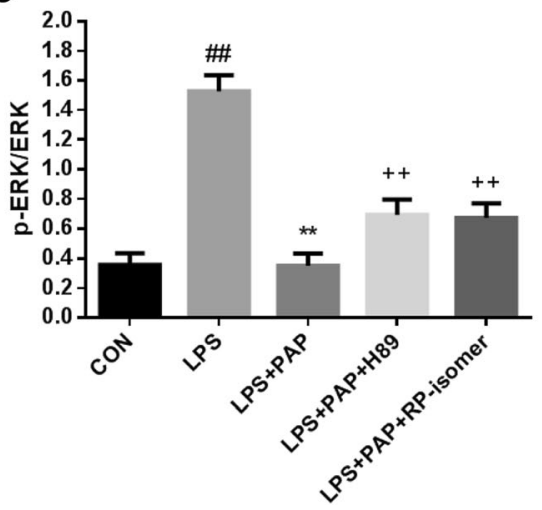

Fig. 7 a-c H89 and Rp-isomer blocked the inhibition of papaverine on the phosphorylated MEK and Erk in LPS-induced microglia. Primary retinal microglia were pretreated with $200 \mu \mathrm{mol} \mathrm{Rp}$-isomer and $5 \mu \mathrm{mol}$ $\mathrm{H} 89$ for $30 \mathrm{~min}$, then treated with $10 \mu \mathrm{g} / \mathrm{ml}$ of papaverine for $4 \mathrm{~h}$, and finally incubated with $100 \mathrm{ng} / \mathrm{ml}$ LPS for $1 \mathrm{~h}$. The cells were lysed, total protein was extracted, and the expression of phosphorylated MEK and Erk were detected by Western Blotting. The results showed that papaverine could block the phosphorylation of MEK and Erk that upregulated by LPS, while Rp-isomer and H89 partly blocked these effects caused by papaverine $(n=6)$. $\# \# P<0.01$ versus $C O N$ group, $* * P<0.01$ versus LPS group, $++P<0.01$ versus LPS+PAP group

$P<0.01$ compared with the LPS group). Precipitating Rpisomer $(0.629 \pm 0.052,0.674 \pm 0.048$, respectively; $n=6$; $P<0.01$ compared with the LPS+PAP group) and H89 $(0.67 \pm 0.046,694 \pm 0.051$, respectively; $n=6 ; P<0.01$ compared with the LPS+PAP group) for $30 \mathrm{~min}$ before the administration of papaverine significantly increased phosphorylated MEK and Erk and partly blocked the effects caused by papaverine.

\section{Discussion}

Our studies indicated that papaverine dose-dependently inhibited the transcription and expression of the inflammatory cytokines TNF- $\alpha$ and IL- $1 \beta$, promoted the expression of the antiinflammatory factor IL-10 of microglia. The above effects were achieved by the cAMP/PKA and MEK/Erk signaling pathway. Then we further investigate the possible mechanism of papaverine and find that papaverine can inhibit the MEK/Erk pathway, thereby inhibiting microglial activation, and MEK/Erk may be regulated by cAMP/PKA. Our results have certain significance as papaverine has been approved by the Food and Drug Administration for the treatment of patients with cerebral thrombosis, pulmonary embolism, arterial spasm, etc. (Zhu et al. 2014; Kim et al. 2014), which is clinically safe. It has been detected through previous studies that conventional doses of papaverine can inhibit retinal microglial activation, which is clinically feasible. Besides, we discovered that papaverine can directly inhibit MEK/Erk pathway and regulate MEK/Erk through cAMP/PKA pathway. We speculate that, together with various upstream factors and downstream substrates, the mechanism of action of papaverine constitutes a functional and responsive signal transduction network.

It is known that after LPS induction, multiple signaling pathways are activated in macrophages (Denlinger et al. 1996). Among these pathways is Erk $1 / 2$ (Lewis et al. 1998; Garrington and Johnson 1999), which is often used as a marker for LPS-induced signal transduction in different cell types (Muller et al. 1993; Sanghera et al. 1996; Schumann et al. 1998; Pyo et al. 1998; Wang et al. 2000). Several studies have suggested that Erk activation is involved in LPS-induced cellular responses, such as the addition of IL-6, TNF- $\alpha$, and NO (Bhat et al. 1998; Carter et al. 1999). Park et al. (2011) found that fucoidan considerably decreased expression of TNF- $\alpha$, IL-1 $\beta$, iNOS, and COX-2 in LPS-induced BV2 cell through inhibiting Erk, Jnk, MAPK, and Akt pathways. The MAPK/ Erk cascade is a significant signaling network associated with cellular development and function. Upon activation of cell surface receptors, cascades of intracellular phosphorylation events are initiated by Ras, Raf, and MEK, to result in the phosphorylation of Erk (Yoon and Seger 2006; Kriegsheim et al. 2009). Neuronal Erk activation is involved in a wide range of activities, including neuronal survival, proliferation, and differentiation, and is a key means of transmitting neurotrophic signals. Similarly, we found that papaverine downregulates the activation of MEK/Erk pathway and reduces the release of inflammatory factors in primary retinal microglia. Our results demonstrate mechanisms involving the 
activation of cAMP, PKA and MEK, Erk, and their cross-talk. Some studies have found that PI3K and PKC lead to ERK activation, which is part of the response of macrophages to inflammatory stimuli (Procyk et al. 1999). Chen et al. also found that apelin activated the expression of inflammatory cytokines in BV2 cells by PI-3K/Akt and MEK/Erk pathways (Chen et al. 2015).

The exact point at which the Erk $1 / 2$ pathway is inhibited by PKA remains to be unclear. Contrastively, PKA has been reported to activate the Erk1/2 pathway and still inhibit cell proliferation (Bornfeldt and Krebs 1999). However, studies have shown that cAMP/PKA stimulates cell proliferation by inhibiting ERK1/2, thereby facilitating activation of the PI-3K pathway (Ciullo et al. 2000). Therefore, the effects of cAMP /PKA on cell proliferation are not identical in views and the specific role of the cAMP /PKA pathway in regulating the Erk1/2 remains unclear. Several studies have discovered that adrenergic receptor (AR) regulates the activation of Erk $1 / 2$ in normal cells by activating cAMP (Enserink et al. 2002; Stork and Schmitt 2002). For example, in cardiac myocytes and bone cells, activation of PKA leads to activation of the Erk1/ 2 pathway (Vossler et al. 1997; Troadec et al. 2002), while in other cell types like adipocytes and endothelial cells, it appears to downregulate Erk1/2 signaling (Schmitt and Stork 2001; Schmitt and Stork 2002). cAMP/PKA regulates Erk in a variety of ways, and some studies have found that inhibitory effects of the cAMP-activated small G protein Rap1, partially reversed reverses cell proliferation and cAMP inhibition of MEK/ERK activation (Hecquet et al. 2002). Besides, some studies have showed that cAMP diminishes expression of SIRT6 by suppressing its ubiquitin-proteasome-dependent degradation, which is mediated by the Raf-MEK-Erk pathway that inhibited by PKA (Kim and Juhnn 2015). In our study, the addition of cAMP inhibitors and PKA inhibitors increased levels of phosphorylated MEK and Erk, and we demonstrated that activation of the MEK/Erk pathway may be partly regulated by cAMP/PKA. Further researches will be needed to elucidate the exact mechanisms of cross-talking between the cAMP/PKA and MEK/ERK pathways and their downstream signaling cascades that inhibit microglia activation.

\section{Conclusions}

Our studies demonstrated that papaverine may inhibit LPSinduced activation of primary retinal microglia through the MEK/Erk pathway, and the MEK/Erk pathway may be partially regulated by cAMP/PKA.

Author Contributions All authors contributed toward the original idea, experimenting, data analysis, drafting the manuscript, and revising the paper. All authors read and approved the final manuscript.
Funding Information This study was supported by the National Natural Science Foundation of China with the reference number 81670856.

\section{Compliance with Ethical Standards}

Conflict of Interest The authors declare that they have no conflict of interest.

Ethical Approval All applicable international, national, and/or institutional guidelines for the care and use of animals were followed.

Open Access This article is distributed under the terms of the Creative Commons Attribution 4.0 International License (http:// creativecommons.org/licenses/by/4.0/), which permits unrestricted use, distribution, and reproduction in any medium, provided you give appropriate credit to the original author(s) and the source, provide a link to the Creative Commons license, and indicate if changes were made.

Publisher's Note Springer Nature remains neutral with regard to jurisdictional claims in published maps and institutional affiliations.

\section{References}

Alam Q, Alam MZ, Mushtaq G, Damanhouri GA, Rasool M, Kamal MA et al (2016) Inflammatory process in Alzheimer and Parkinson's diseases: central role of cytokines. Curr Pharm Des 22(5):541-548

Bhat NR, Zhang P, Lee JC, Hogan EL (1998) Extracellular signalregulated kinase and $\mathrm{p} 38$ subgroups of mitogen-activated protein kinases regulate inducible nitric oxide synthase and tumor necrosis factor- $\alpha$ gene expression in endotoxin-stimulated primary glial cultures. J Neurosci 18(5):1633-1641

Bornfeldt KE, Krebs EG (1999) Crosstalk between protein kinase a and growth factor receptor signaling pathways in arterial smooth muscle. Cell Signal 11(7):465-477

Brown GC, Neher JJ (2014) Microglial phagocytosis of live neurons. Nat Rev Neurosci 15:209-216

Buttini M, Mir A, Appel K, Wiederhold KH, Limonta S, Gebicke-Haerter PJ, Boddeke HWGM (1997) Lipopolysaccharide induces expression of tumour necrosis factor alpha in rat brain: inhibition by methylprednisolone and by rolipram. Br J Pharmacol 122:1483-1489

Carter AB, Monick MM, Hunninghake GW (1999) Both Erk and p38 kinases are necessary for cytokine gene transcription. Am J Respir Cell Mol Biol 20:751-758

Chen L, Tao Y, Jiang Y (2015) Apelin activates the expression of inflammatory cytokines in microglial BV2 cells via PI-3K/Akt and MEK/ Erk pathways. Sci China Life Sci 58(6):531-540

Ciullo I, Diez-Roux G, DI-Domenico M, Migliaccio A, Avyedimento EV (2000) cAMP signaling selectively influences Ras effectors pathways. Oncogene 20(10):1186-1192

Dang Y, Xu Y, Wu W, Li W, Sun Y, Yang J, Zhu Y, Zhang C (2014) Tetrandrine suppresses lipopolysaccharide-induced microglial activation by inhibiting NF-KB and ERK signaling pathways in BV2 cells. PLoS One 9(8):e102522

Denlinger LC, Fisette PL, Garis KA, Kwon G, Vazquez-Torres A, Simon AD (1996) Regulation of inducible nitric oxide synthase expression by macrophage purinoreceptors and calcium. J Biol Chem 271(1): 337-342

Enserink JM, Christensen AE, de Rooij J, van Triest M, Schwede F, Genieser HG, Døskeland SO, Blank JL, Bos JL (2002) A novel Epac-specific cAMP analogue demonstrates independent regulation of Rap1 and ERK. Nat Cell Biol 4:901-906 
Garrington TP, Johnson GL (1999) Organization and regulation of mitogen-activated protein kinase signaling pathways. Curr Opin Cell Biol 11(2):211-218

Ghosh M, Garcia-Castillo D, Aguirre V, Golshani R, Atkins CM, Bramlett HM, Dietrich WD, Pearse DD (2012) Proinflammatory cytokine regulation of cyclic AMP-phosphodiesterase 4 signaling in microglia in vitro and following CNS injury. Glia 60:1839-1859

Hecquet C, Lefevre G, Valtink M, Engelmann K, Mascarelli F (2002) cAMP inhibits the proliferation of retinal pigmented epithelial cells through the inhibition of ERK1/2 in a PKA-independent manner. Oncogene 21(39):6101-6112

Iannotti C, Ping Zhang Y, Shields CB, Han Y, Burke DA, Xu X-M (2004) A neuroprotective role of glial cell line-derived neurotrophic factor following moderate spinal cord contusion injury. Exp Neurol 189(2):317-332

Kettenmann H, Hanisch U-K, Noda M, Verkhratsky A (2011) Physiology of microglia. Physiol Rev 91:461-553

Kim EJ, Juhnn YS (2015) Cyclic AMP signaling reduces Sirtuin 6 expression in non-small cell lung cancer cells by promoting ubiquitinproteasomal degradation via inhibition of the Raf-MEK-ERK pathway. J Biol Chem 290(15):9604-9613

Kim WK, Hwang SY, Oh ES, Piao HZ, Kim KW, Han IO (2004) TGF- $\beta 1$ represses activation and resultant death of microglia via inhibition of phosphatidylinositol 3-kinase activity. J Immunol 172:7015-7023

Kim JH, Yi H-J, Ko Y, Kim Y-S, Kim D-W, Kim J-M (2014) Effectiveness of papaverine cisternal irrigation for cerebral vasospasm after aneurysmal subarachnoid hemorrhage and measurement of biomarkers. Neurol Sci 35:715-722

Kriegsheim A, Baiocchi D, Birtwistle M, Sumpton D, Bienvenut W, Morrice N, Yamada K, Lamond A, Kalna G, Orton R, Gilbert D, Kolch W (2009) Cell fate decisions are specified by the dynamic ERK interactome. Nat Cell Biol 11:1458-1464

Lewis TS, Shapiro PS, Ahn NG (1998) Signal transduction through MAP kinase cascades. Adv Cancer Res 74:49-139. https://doi.org/10. 1016/S0065-230X(08)60765-4

Loane DJ, Kumar A (2016) Microglia in the TBI brain: the good, the bad, and the dysregulated. Exp Neurol $275 \mathrm{Pt}(3): 316-327$

Milner R, Campbell IL (2002) Cytokines regulate microglial adhesion to laminin and astrocyte extracellular matrix via protein kinase Cdependent activation of the alpha6beta1 integrin. J Neurosci 22(5): $1562-1572$

Mizuno T, Kurotani T, Komatsu Y, Kawanokuchi J, Kato H, Mitsuma N, Suzumura A (2004) Neuroprotective role of phosphodiesterase inhibitor ibudilast on neuronal cell death induced by activated microglia. Neuropharmacology 46:404-411

Muller JM, Ziegler-Heitbrock HW, Baeuerle PA (1993) Nuclear factor kappa B, a mediator of lipopolysaccharide effects. Immunobiology 187(3-5):233-256

Namiki J, Kojima A, Tator CH (2000) Effect of brain-derived neurotrophic factor, nerve growth factor, and neurotrophin-3 on functional recovery and regeneration after spinal cord injury in adult rats. J Neurotrauma 17(12):1219-1231

Park HY, Han MH, Park C, Jin CY, Kim GY, Choi IW, Kim ND, Nam TJ, Kwon TK, Choi YH (2011) Anti-inflammatory effects of fucoidan through inhibition of NF-kappaB, MAPK and Akt activation in lipopolysaccharide-induced BV2 microglia cells. Food Chem Toxicol 49:1745-1752

Pousset F, Cremona S, Dantzer R, Kelley K, Parnet P (1999) Interleukin-4 and interleukin-10 regulate IL1-beta induced mouse primary astrocyte activation: a comparative study. Glia 26(1):12-21

Procyk KJ, Kovarik P, von Gabain A, Baccarini M (1999) Salmonella typhimurium and lipopolysaccharide stimulate extracellularly regulated kinase activation in macrophages by a mechanism involving phosphatidylinositol 3-kinase and phospholipase D as novel intermediates. Infect Immun 67(3):1011-1017

Pyo H, Jou I, Jung S, Hong S, Joe EH (1998) Mitogen-activated protein kinases activated by lipopolysaccharide and $\beta$-amyloid in cultured rat microglia. NeuroReport 9(5):871-874

Sanghera JS, Weinstein SL, Aluwalia M, Girn J, Pelech SL (1996) Activation of multiple proline-directed kinases by bacterial lipopolysaccharide in murine macrophages. J Immunol 156(11):44574465

Schafer P (2012) Apremilast mechanism of action and application to psoriasis and psoriatic arthritis. Biochem Pharmacol 83:1583-1590

Schmitt JM, Stork PJ (2001) Cyclic AMP-mediated inhibition of cell growth requires the small G protein Rap1. Mol Cell Biol 21:36713683

Schmitt JM, Stork PJ (2002) PKA phosphorylation of Src mediates cAMP's inhibition of cell growth via Rap1. Mol Cell 9:85-94

Schumann RR, Pfeil D, Freyer D, Buerger W, Lamping N, Kirschning CJ, Weber JR (1998) Lipopolysaccharide and pneumococcal cell wall components activate the mitogen activated protein kinases (MAPK) erk-1, erk-2, and p38 in astrocytes. Glia 22(3):295-305

Sivakumar V, Foulds WS, Luu CD, Ling E-A, Kaur C (2011) Retinal ganglion cell death is induced by microglia derived proinflammatory cytokines in the hypoxic neonatal retina. J Pathol 224:245-260

Stork PJ, Schmitt JM (2002) Crosstalk between cAMP and MAP kinase signaling in the regulation of cell proliferation. Trends Cell Biol 12: 258-266

Tanuma N, Sakuma H, Sasaki A, Matsumoto Y (2006) Chemokine expression by astrocytes plays a role in microglia/macrophage activation and subsequent neurodegeneration in secondary progressive multiple sclerosis. Acta Neuropathol 112(2):195-204

Troadec JD, Marien M, Mourlevat S, Debeir T, Ruberg M, Colpaert F, Michel PP (2002) Activation of the mitogen-activated protein kinase (ERK(1/2)) signaling pathway by cyclic AMP potentiates the neuroprotective effect of the neurotransmitter noradrenaline on dopaminergic neurons. Mol Pharmacol 62:1043-1052

Vossler MR, Yao H, York RD, Pan MG, Rim CS, Stork PJ (1997) cAMP activates MAP kinase and Elk-1 through a B-Raf- and Rap1dependent pathway. Cell 89:73-82

Wang PL, Azuma Y, Shinohara M, Ohura K (2000) Toll-like receptor 4mediated signal pathway induced by Porphyromonas gingivalis lipopolysaccharide in human gingival fibroblasts. Biochem Biophys Res Commun 273(3):1161-1167

Woo M-S, Jung S-H, Hyun J-W, Kim H-S (2004) Differential regulation of inducible nitric oxide synthase and cytokine gene expression by forskolin and dibutyryl-cAMP in lipopolysaccharide-stimulated murine BV2 microglial cells. Neurosci Lett 356:187-190

Yoon S, Seger R (2006) The extracellular signal-regulated kinase: multiple substrates regulate diverse cellular functions. Growth Factors 24: 21-44

Yoshikawa M, Suzumura A, Tamaru T, Takayanagi T, Sawada M (1999) Effects of phosphodiesterase inhibitors on cytokine production by microglia. Mult Scler 5:126-133

Zhang Y, Dong C (2007) Regulatory mechanisms of mitogen-activated kinase signaling. Cell Mol Life Sci 64:2771-2789

Zhu W, Liu S, Zhao J, Liu S, Jiang S, Li B, Yang H, Fan C, Cui W (2014) Highly flexible and rapidly degradable papaverine-loaded electrospun fibrous membranes for preventing vasospasm and repairing vascular tissue. Acta Biomater 10(7):3018-3028 